\title{
Appetitive learning relies on octopamine and dopamine in ants
}

\author{
Maarten Wissink, Volker Nehring
}

Evolutionary Biology \& Ecology, Institute for Biology I (Zoology), University of Freiburg, Freiburg, Germany

Correspondence: volker.nehring@biologie.uni-freiburg.de; Tel.: +49 (0)761 203-2584. Fax: +49 761203 2544.

\section{Abstract}

5 Associative learning relies on the detection of coincidence between a stimulus and a

6 reward or punishment. In the insect brain, this process is thought to be carried out in the

7 mushroom bodies under control of octopaminergic and dopaminergic neurons. It was

8 assumed that appetitive learning is governed by octopaminergic neurons, while

9 dopamine is required for aversive learning. This view has been recently challenged:

10 Both neurotransmitters seem to be involved in both types of memory in bees and flies.

11 Here, we test which neurotransmitters are required for appetitive learning in ants. We

12 trained Lasius niger ant workers to discriminate two mixtures of linear hydrocarbons

13 and associate one of them with a sucrose reward. We analysed the behaviour of the

14 trained ants using machine learning and found that they preferred the rewarded odour

15 over the other, a preference that was stable for at least 24 hours. We then treated the ants

16 before learning with either epinastine, an octopamine receptor blocker, or with

17 flupentixol, a dopamine receptor blocker. Ants with blocked octopamine receptors did

18 not remember the rewarded odour. Octopamine signalling is thus necessary for the

19 formation of appetitive memory. In contrast, ants with blocked dopamine receptors

20 initially learned the rewarded odour but failed to retrieve this memory 24 hours later.

21 Dopamine is thus required for long-term memory consolidation during appetitive

22 conditioning, independent of short-term memory formation. Our results show that

23 appetitive learning depends on both octopamine and dopamine signalling in ants.

24 key words: associative learning, Lasius niger, long term memory, neurotransmitters,

25 short term memory 


\section{Introduction}

27 There is nothing stable in the world; those that can adapt to changes will prevail. When

28 the profitability of food sources changes over time, it would be advantageous to quickly

29 learn which ones are currently most rewarding. Individuals can do so by associating the

30 food with other stimuli such as odours or colours, i.e. they establish a predictive

31 relationship between two independent cues from the environment (Giurfa, 2007). When

32 a neutral stimulus, like an odour, is paired with a biologically relevant stimulus (food,

33 the unconditioned stimulus - US), the animal may in future react to the previously

34 neutral odour (the now conditioned stimulus - CS), as if it were the US. In the case of a

35 bee searching for food, CS and US are processed by two different pathways. The CS-

36 pathway starts at the odorant receptors (ORs) in the antenna. Output from the OR

37 neurons is first processed in the antennal lobe (Giurfa, 2007). From there, projection

38 neurons carry the information to the mushroom bodies, where learning occurs. The US-

39 pathway begins at gustatory receptors on the mouth parts. Neurons then project to the

40 subesophageal ganglion, from where the octopaminergic VUMx1-neuron projects to the

41 antennal lobe and the mushroom bodies (Giurfa, 2007; Galizia and Sachse, 2010; Perry

42 and Barron, 2013). CS and US converge in the Kenyon Cells of the mushroom body,

43 which act as coincidence detectors. In their normal state, they would not relay a specific

44 odour to the higher brain centres through mushroom body output neurons. However,

45 after an odour coincided with an US, the Kenyon cells will relay the odour as a now

46 conditioned stimulus, even in absence of the US.The reliance of the US signalling on

47 the octopaminergic VUMx neuron suggests that without octopamine (OA) signalling,

48 the US cannot reach the MB and thus insects cannot learn. Indeed, blocking OA

49 receptors in crickets, flies, and honeybees prevented appetitive memory formation and

50 memory retrieval (Schwaerzel et al., 2003; Galizia and Sachse, 2010), while OA

51 injections could replace the US (Hammer and Menzel, 1998). Similar experiments

52 blocking dopamine (DA) receptors had no effect on appetitive learning but prevented

53 individuals from associating a punishment, such as an electric shock, with odours or

54 colours (aversive conditioning; Schwaerzel et al., 2003; Vergoz et al., 2007; Mizunami

55 and Matsumoto, 2017). It was thus assumed that aversive and appetitive memory are

56 formed in different modules of the antennal lobes that use different neurotransmitters 
57 (Hige et al., 2015). To this day, this seems to hold true for crickets (Mizunami and

58 Matsumoto, 2017), but newer data suggest that aversive conditioning relies on both OA

59 and DA signalling in honeybees and fruit flies (Agarwal et al., 2011; Claßen and Scholz,

60 2018; Manicini et al., 2018). The use of Drosophila GAL4 lines that can be used to

61 knock out specific neurons in the MB has allowed to paint a much more detailed picture

62 of learning and memory retrieval: In flies, learning in the MB appears to be organized in

63 modules that each consist of Kenyon cells, mushroom body output neurons, and

64 dopaminergic neurons that modulate the valence of the modules (Berry et al., 2012;

65 Hige et al., 2015.) Some of the modules organize attraction to odours, and others

66 repulsion (Rohwedder et al., 2016). The modules further differ in how long the memory

67 lasts - from a few seconds to several hours (also in honeybees: Menzel, 2014). The

68 control of both appetitive and aversive learning by dopaminergic neurons also means

69 that without dopamine signalling, both types of learning should be hampered, which

70 matches the behavioural evidence from pharmacological receptor blocking and

71 knockouts in Drosophila and honeybees (Berry et al., 2012; Perisse et al., 2013; Perry

72 and Barron, 2013; Mancini et al., 2018; Sabandal et al., 2020).

73 One way to hinder dopamine- and octopamine-related signalling is to block their

74 respective receptors pharmacologically. In insects, epinastine is a specific OA-receptor

75 blocker which abolishes the OA related cAMP production in the mushroom bodies

76 (Roeder et al., 1998). Epinastine seems to specifically target the AmOA1 receptor in

77 honey bees (Beggs et al., 2011), the OA1 receptor in crickets (Awata et al., 2015), the

78 DmOA3 receptor in Drosophila (Qi et al., 2017), and the and NcOA2B2 receptor in the

79 green rice leafhopper Nephotettix cincticeps (Xu et al., 2020). In contrast, flupentixol

80 largely targets dopamine receptors, such as the AmDOP2 receptor in the mushroom

81 bodies of honey bees (Mustard et al., 2003; 2010; Beggs et al., 2011).

82 Just like honey bees, ants are social insects for whom learning is important in many

83 contexts (Bos et al., 2010). Ants can learn odours of rewarding food sources and also

84 have to learn the specific odour of their own colony (Neupert et al., 2018). Indeed, ants

85 can perform similar learning tasks as bees and other insects (Bos et al., 2010, Guerrieri

86 and d'Ettorre, 2010; Fernandes et al., 2018; Piqueret et al., 2019). In addition to floral

87 odours that might signal food sources, ants were successfully conditioned to 
88 hydrocarbons that play an important role in social interactions (Bos et al., 2012, Sharma

89 et al., 2015). For example, hydrocarbons can serve as alarm and queen pheromones, and

90 are used to discriminate nestmates from non-nestmates (Leonhard et al., 2016). While it

91 has been found that protein synthesis is important for the formation of the long term

92 memory in Camponotus ants (Guerrieri et al., 2011), we know nothing about the neural

93 circuits of learning in the ants, nor of the role different neurotransmitters play in ant

94 learning.

95 Here, we study reward learning the black garden ant Lasius niger. First, we established

96 an assay that trained the ants to associate a mixture of linear hydrocarbons to a sugar

97 reward. We tested the memory retrieval after 5 minutes and after one day using a deep

98 learning algorithm on videos of reward-searching ants. In a second step, we

99 administered epinastine or flupentixol via either the food or topical application, to block

100 OA and DA receptors and to test if a breakdown of the respective neural pathways

101 would prevent the ants from forming short- and long-term memories of the odour-

102 reward association. 


\section{Material and Methods}

104 We trained ants to discriminate two mixtures of n-alkanes, one of which was presented

105 with a sugar reward and the other was unrewarded, during six rounds of training trials.

106 After that, we ran retention tests without sugar reward to see whether the ants now

107 preferred the previously rewarded odour (conditioned stimulus - CS+) over the

108 unrewarded odour (CS0). A first retention test was conducted ten minutes after the final

109 learning trial to test the short term memory capabilities. The second retention test was

110 performed one day later to test the (early) long term memory (Menzel, 1999).

111 Before the learning trials, we submitted the ants to treatments with blockers of

112 octopamine receptors, dopamine receptors, or controls. The drugs were administered

113 either with food (set 1 ) or by topical application on the mesothorax (set 2). The two

114 experimental sets also differed in the way we recorded the data (manual vs. automated

115 recording, see Experimental Setup).

\section{Experimental Organism}

117 Colonies of black garden ants Lasius niger (Linnaeus, 1758) were collected in the years 1182017 and 2019 in Freiburg, Germany. They were transported to the laboratory and kept 119 in plastic boxes at $20^{\circ} \mathrm{C}$, a $12: 12$ light:dark cycle, and were fed with meal-worms 120 (Tenebrio molitor) and honey. Test tubes filled with water, cotton wool, and an 121 aluminium foil wrapping were placed in the boxes as a refuge and a water source. The 122 boxes' walls were lined with Fluon ${ }^{\circledR}$ (AGC Chemicals Europe, Ltd.). Around two 123 weeks before an experiment, the ants were deprived of honey and only fed mealworms, 124 in order to motivate them to forage for carbohydrates. We used four different source 125 colonies for the experiments in set 1 , and 11 different source colonies for set 2.

\section{Stimuli}

127 Two mixtures of three long-chain linear alkanes each were used as the two conditioned

128 stimuli (CS). The first mixture (CS-mixture A) was n-octadecane (n-C18), n-

129 heneicosane (n-C21), and n-heptacosane (n-C27). The second (CS-mixture B) was n-

130 eicosane (n-C20), n-docosane (n-C22), and n-pentacosane (n-C25; all Sigma-Aldrich, 
131 Steinheim, Germany). The hydrocarbons were solved in n-pentane (10 $\mu \mathrm{g} / \mathrm{ml})$ that

132 would evaporate before the experiments. In a preliminary experiment, we used the

133 retention test setup (see below) with untrained ants to see if they preferred any of the

134 two odour mixtures over the other. The untrained ants spent similar times with the two

135 odour mixtures $(n=30$, wilcoxon test $V=253, p=0.69$; Figure $S 1)$. A $0.5 \mu L$ drop of

136 sugar water (50\% w/w) or pure water were used as a positive unconditioned stimulus

137 (US+) and neutral unconditioned stimulus, respectively.

\section{Experimental Setup}

139 For the first set of experiments (feeding experiment) the test arena was the top of a petri

140 dish (90 mm in diameter). Another petri dish lid was used as a roof, and a hole (40 mm

141 in diameter) was cut into the roof to allow placing the ants into the arena. The ants were

142 recorded from a $45^{\circ}$ angle by a Nikon D90 with a $35 \mathrm{~mm}$ lens, which was placed in front

143 of the arena on a tripod. For the second set of experiments (topical application), an

144 acrylic glass cylinder (100 mm diameter - $100 \mathrm{~mm}$ height) was used as an arena. The

145 arena was covered by a cardboard box lined with aluminium foil to exclude external

146 stimuli and to allow for even illumination by two light sources above the arena. The ants

147 were videotaped with a SM-P600 tablet computer at 1.5x magnification, the lens of

148 which was placed directly above the centre of the arena.

149 For both sets of experiments, the walls of the arena were coated with Fluon to prevent

150 the ants from climbing. The floor was lined with filter paper that was evenly divided

151 into quarters. A microscope cover slip (24×24 mm) was placed in the centre of each

152 quadrant (Fig. 1A). In each learning and test trial, one of the cover slips was coated with

$15320 \mu \mathrm{L}$ of odour $\mathrm{A}$, another with odour $\mathrm{B}$, and the remaining two with pure pentane. The

154 solutions were always applied to the edges of the cover slips. After every trial, the filter

155 paper and cover slips were replaced with new ones. 

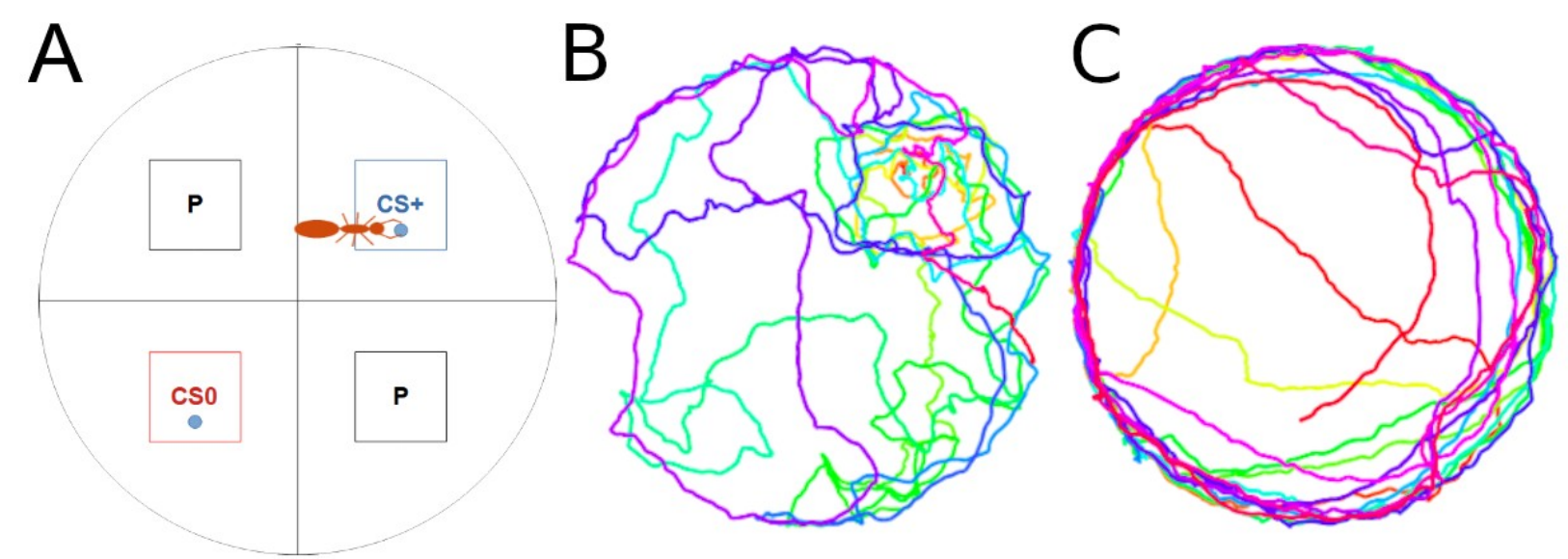

Figure 1 A) Design of the experimental arena used for the learning experiments. The arena was divided into four quadrants, each with a cover slip in it. One of the cover slips was coated with odour A, another one with odour B. During the learning experiments, one of the odours was paired with sucrose solution and the other with water. B, C) Traces of ants during the retention tests with the rewarded odour in the top right quadrant. The ant in B inspected the $\mathrm{CS}+$, the ant in panel $\mathrm{C}$ did not show any particular interest in the previously rewarded odour. Colours show how the ants moved from the beginning of the test (red) to the end (blue).

\section{Learning Trials}

159 The learning procedure was adapted from Bos et al.'s (2010, 2012) work on ant

160 learning. From the main colony, around 30 ants that were moving outside of the nest

161 tubes were separated into a box equipped with nest tubes like the source colonies were.

162 Here, ants could perform trophallaxis between the trials, to reduce their sugar storage

163 and increase the motivation to forage again. The ants were marked on the gaster with a

164 small dot of paint (Edding No. 751), so that it was possible to individually track them

165 between the learning trials.

166 For each learning trial, $0.5 \mu \mathrm{l}$ of sugar solution was added to the cover slips with one of

167 the odours (CS+), while water was added to the slip with the CS0. For each ant, the

168 same odour was rewarded in each learning trial, but which odour was rewarded differed

169 randomly between ants. An individual ant was then lifted gently into the arena and the

170 time was measured until it began drinking the sugar solution. Then, the ant was 
171 removed to prevent it from consuming too much sugar solution, and placed back into

172 the experimental colony where it could perform trophallaxis with the nestmates. After

173 six minutes, when trophallaxis was always complete, the ant was brought back into the

174 arena for the next learning trial. In total, there were six learning trials per individual.

175 If an ant had not found the sugar solution within 3 minutes in set 1 , she was removed

176 from the learning arena and brought back into the experimental colony until the next

177 learning trial. Ants that could not find the sugar solution in two or more learning trials

178 were excluded from the analysis. The process was similar for set two, but we gave the

179 ants only two minutes for the second through sixth learning trial, because the results

180 from set 1 showed that times longer than 2 minutes are very rare in the later trials. We

181 began set 1 with 180 ants across the six treatments and excluded 14 of those. In set 2,

182 we had to exclude 9 out of 189 ants. The highest proportion of excluded ants came from

183 flupentixol treatments in both sets (Table S1). There was no difference between

184 treatments when we fed the receptor blockers $\left(\mathrm{X}^{2}{ }_{5}=8.5, \mathrm{p}=0.13\right.$, $\mathrm{p}$-value calculated by

185 Monte Carlo simulation). In the topical application experiment, the treatments differed

186 in the likelihood of ants failing $\left(x^{2}{ }_{3}=10.7, p=0.02\right)$, although overall only 2 ants were

187 excluded, both from the flupentixol treatment.

188 We tested whether the ants became quicker to find the sugar solution during the

189 consecutive learning trials with a poisson MCMC glmm, with time until finding the

190 sugar as the dependent variable and trial number as a continuous predictor, for each

191 treatment separately. We entered the colony ID and individual ant ID as random factors

192 into the model using the R package MCMCglmm with 50000 MCMC iterations and

193 otherwise default settings (R version 4.0.3 - R Core Team ,2020; Hadfield, 2010). In set

194 2, we observed the ants for only 2 minutes in learning trials 2-6, as opposed to 3

195 minutes in trial 1 . To exclude that the few ants taking longer than 2 minutes in trial 1

196 already cause a downward trend in the learning times across trials, we set the times of

197 all ants that took longer than 2 minutes to 2 minutes for the glmm but left all times

198 shorter than two minutes as they were. 


\section{Retention Tests}

201 When the ants had finished trophallaxis after the sixth learning trial, a first retention test

202 was conducted. Retention tests resembled training trials but no sugar solution or water

203 was added to any of the cover slips. The cover slips with the CS+ and CS0 odours were

204 in opposite quadrants (Fig. 1A). Each ant was recorded for two minutes. Then, a drop of

205 sugar water was placed on the cover slip with the learned odour to prevent extinction

206 before the retention trials on the following day. When the ant had finished to eat, it was

207 lifted back into the test colony. The position of the cover slips was changed and the ant

208 was recorded a second time. The duration spent in the different quadrants was averaged

209 over the two tests for each ant. On the next day, the same ants were tested again to see if

210 they could still remember the CS+. The marked ants were kept in isolation over night

211 together with the other ants from the same colony that were treated on this day. The

212 interval between the two test trials was 15-23 hours.

213 The time the ants spent in the four quadrants was measured from the video recordings.

214 In set 1, times were measured manually using the program etholog (Ottoni, 2000). For

215 the second set, the deep learning algorithm DeepLabCut (Mathis et al. 2018) was used.

216 The algorithm was trained to spot the ant and record its coordinates using 200 frames

217 from each of 20 pre-recorded videos, in which the position of the ant was marked

218 manually. Then, the algorithm went over these frames 200,000 times to perfect its ant

219 recognition performance. After this, the first videos from the experiments were

220 processed with the algorithm and manually checked for errors. Only few errors were

221 detected and then used to further improve the algorithm, which was virtually perfect

222 after ca. 10 videos. In total, 756 videos were used for data analyses.

223 From the ant's coordinates, we could calculate in how many frames the ant was

224 identified in each of the four quadrants, and thus how much time it spent there. We

225 directly compared whether the ants spent more time on one of the two odour mixtures

226 using paired wilcoxon tests. In addition, we calculated and visualized (ggplot2 -

227 Wickham, 2016) a preference index as an intuitive measurement of preference and

228 hence learning performance based on the times ( $\mathrm{t}$ ) on the different odours (Bos et al.

229 2010, 2012): 


$$
P I=\frac{t_{\mathrm{CS}+}-t_{\mathrm{CS}-}}{t_{\mathrm{CS}+}+t_{\mathrm{CS}-}}
$$

231 The index ranges from 1 (preference for the CS+) to -1 (preference for the CS0). If the

232 ant spent an equal amount of time on both odours, the PI would be 0.

\section{Pharmalogical Manipulations}

234 To test in how far neurotransmitters are involved in appetitive learning, the ants were

235 treated with one of two different receptor blockers before the learning trials: epinastine,

236 an octopamine receptor blocker (Kamhi et al., 2015), or flupentixol, a dopamine

237 receptor blocker (Agarwal et al., 2011).

238 For the first set of experiments, ants were fed honey infused with the blocker (20 mM of

239 epinastine hydrochloride or $50 \mathrm{mM}$ of flupentixol hydrochloride) either 1-3 hours, 5-8

240 hours, or 17 hours prior to the experiment. The ants were individually fed with a $1 \mu \mathrm{L}$

241 drop of this solution. The different intervals were chosen because it was not clear how

242 long it takes for the drugs after feeding to become effective. The honey with the drug

243 was coloured with neutral red to control if the ants had indeed ingested the honey. Only

244 ants with a red staining in their gaster were chosen for the experiments. When the ants

245 had finished eating, they were kept in groups with other ants that had received the same

246 drug, until the start of the learning trials. Immediately before the beginning of its

247 learning trial, each ant was marked with the paint marker and moved back to a

248 subcolony of ca. 30 ants set up for this purpose. Control ants were fed pure honey

249 instead of blocker-infused honey.

250 For the second set of experiments, the drugs were dissolved in dimethylformamide

251 (DMF), and a 0.5 $\mu$ l droplet directly applied to the ant's cuticula on the mesothorax

252 (Barron et al., 2007). The ants were allowed to recover from the treatment for 15

253 minutes in isolation, after which they were paint-marked and returned 5 minutes later to

254 the subcolonies as described above. Another 10 minutes later, the first learning trial

255 began. For epinastine, the two dosages were $20 \mathrm{mM}$ or $100 \mathrm{mM}$ in DMF, corresponding

256 to doses of $1.8 \mathrm{ng} / \mu \mathrm{g}$ and $9.1 \mathrm{ng} / \mu \mathrm{g}$ of ant body weight. For flupentixol, the dosage was

$257250 \mathrm{mM}(39.3 \mathrm{ng} / \mu \mathrm{g})$. Control ants received pure DMF. 
bioRxiv preprint doi: https://doi.org/10.1101/2021.04.19.438615; this version posted April 19, 2021. The copyright holder for this preprint (which was not certified by peer review) is the author/funder, who has granted bioRxiv a license to display the preprint in perpetuity. It is made available under aCC-BY-ND 4.0 International license.

11

258 We compared the preference indices (PI) among treatments with MCMC glmms with

259 treatment as the only predictor, so that we could test for each treatment whether it

260 differed from the control. Colony ID was entered into the model as a random factor. In

261 the same manner, we compared the walking speed of ants, calculated from the

262 coordinates generated during set 2 , among the different treatments. 


\section{Results}

\section{Set 1: Feeding of receptor blockers}

265 Over the successive learning trials, control-treated ants became quicker in finding the

266 sugar reward (Fig. 2, poisson glmm $\mathrm{p}=0.04, \mathrm{n}=30$ ants), indicating that they learned

267 to associate the rewarded odour with the sugar reward. This was also true for all

268 treatments with receptor blockers (epinastine 1-3h p $<0.001, \mathrm{n}=27$ ants; epinastine 5-

$2698 \mathrm{~h} \mathrm{p}<0.001, \mathrm{n}=29$ ants; epinastine 17-26h $\mathrm{p}=0.02, \mathrm{n}=25$ ants; flupentixol 1-3h $\mathrm{p}=$

$2700.04, \mathrm{n}=26$ ants, Fig. 2), with the exception of the ants that were treated with

271 flupentixol 5-8h before the first learning trial $(\mathrm{p}=0.50, \mathrm{n}=21$ ants).

272 In the first retention test 10 minutes after the last learning trial, the ants were able to

273 differentiate between CS+ and CS0, independent of treatment (Figure 3A, wilcoxon-

274 tests $\mathrm{p}<0.05$ ). Only the ants that were fed with flupentixol 5-8h before the treatment

275 had difficulties to differentiate between CS + and CS0 (wilcoxon test $p=0.052$ ). In most

276 treatments, the preference indices were indistinguishable from that of control ants

277 (glmms p > 0.16; Tab. S2 for details), but the PIs of ants treated with flupentixol 1-3

278 hours before the learning trials were lower than those of control ants (glmm $p=0.045$ ),

279 and there was a similar trend for the preference indices of ants treated with epinastine 5-

2808 hours before the learning trials $(\mathrm{p}=0.07)$. On the second day (Figure $3 \mathrm{~B})$, the control

281 ants and some of the epinastine-treated (5-8 hours and 17-26 hours before the learning

282 trials) ants still differentiated between CS+ and CS0 (wilcoxon test $\mathrm{p}<0.05$ ). In

283 contrast, ants that were treated with epinastine 1-3 hours before the experiment, and the

284 ants from both flupentixol treatments were not able to differentiate between CS+ and

285 CS- (wilcoxon tests $\mathrm{p}>0.05$ ). However, there was no difference in the preference

286 indices between the treatments (glmm p > 0.5; Tab. S2), with the exception of ants

287 treated with epinastine 1-3 hours before the learning trials, for which there was a trend

288 of the PIs being lower than those of control ants $(p=0.06)$. 
bioRxiv preprint doi: https://doi.org/10.1101/2021.04.19.438615; this version posted April 19,2021 . The copyright holder for this preprint (which was not certified by peer review) is the author/funder, who has granted bioRxiv a license to display the preprint in perpetuity. It is made available under aCC-BY-ND 4.0 International license.
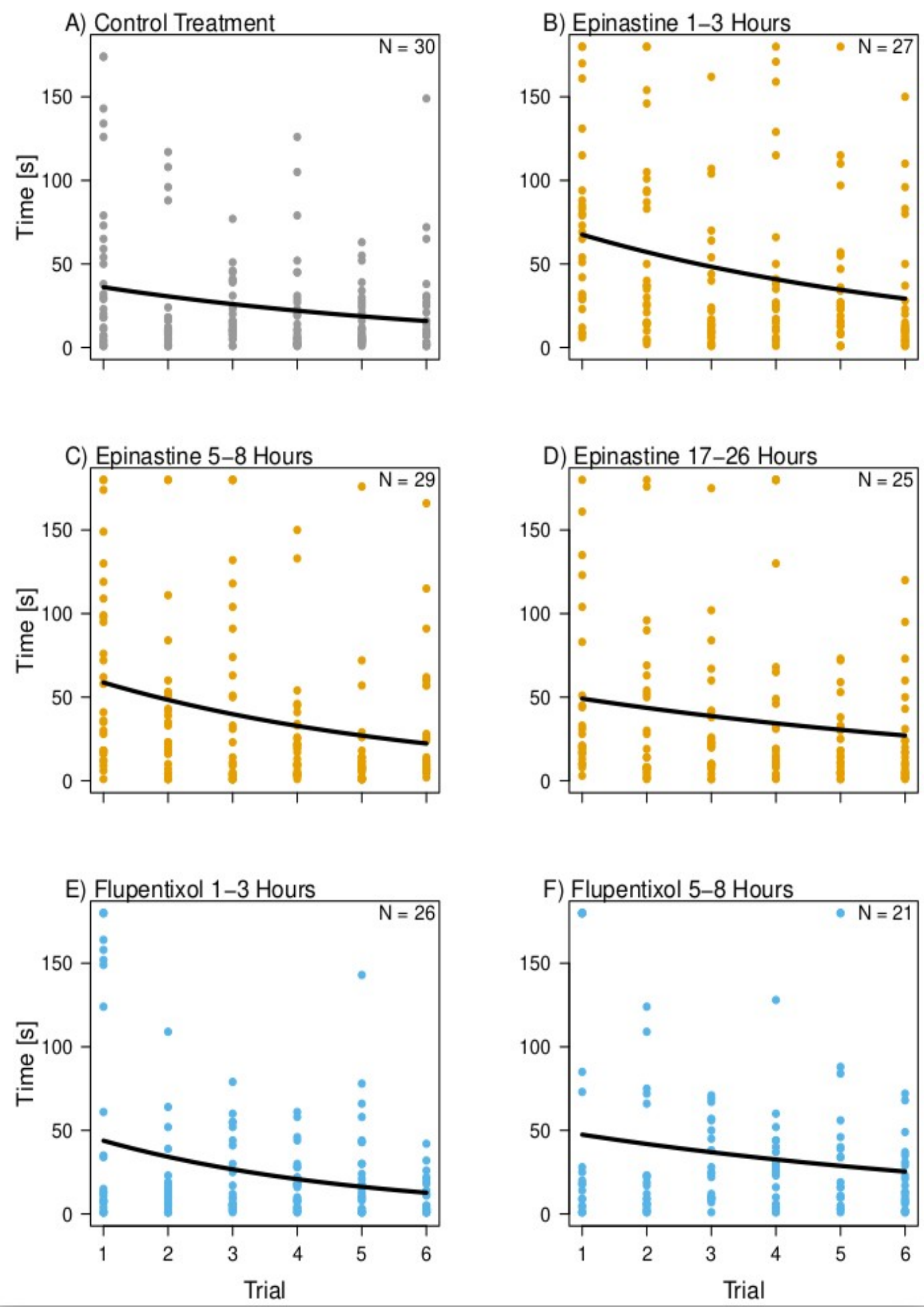

Figure 2: The time it took ants to find the sugar reward in six consecutive learning trials. Ants were either control treated (a), or received epinastine $(b-d)$ or flupentixol $(e, f)$ with their food at different intervals before the first learning trials (1-3 hours, 5-8 hours, 17-26 hours). Individual data points are plotted; the lines are poisson regressions. 
A) Day 1

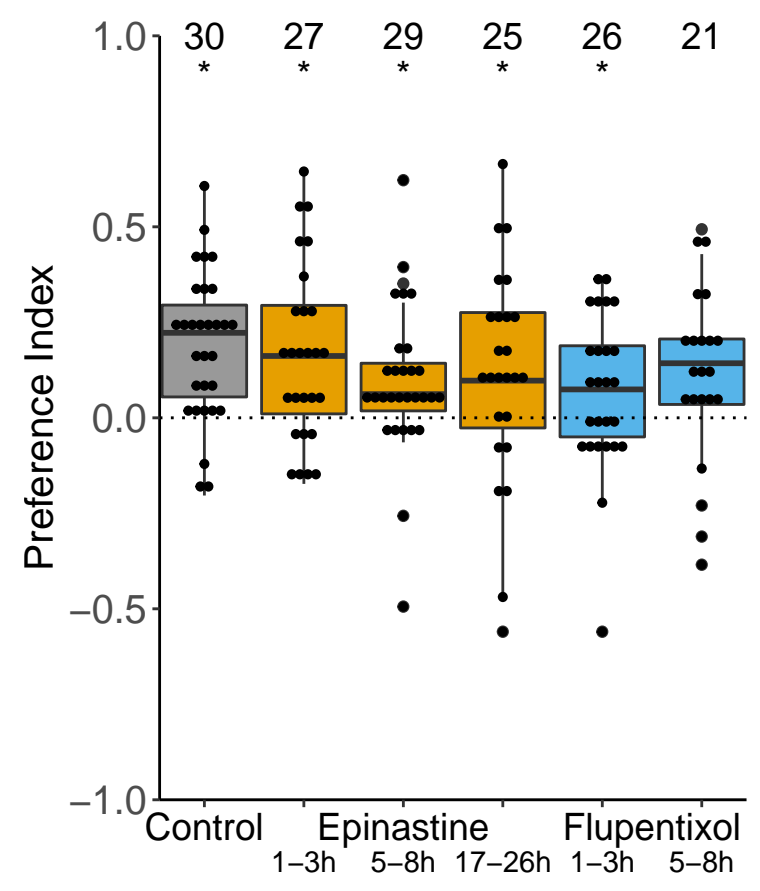

B) Day 2

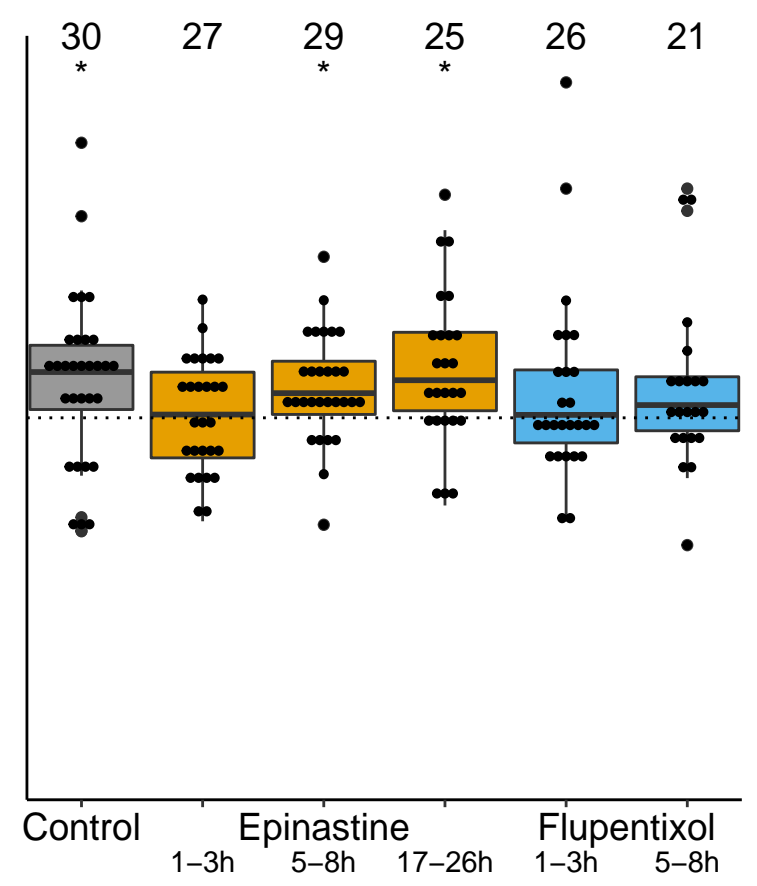

Figure 3: Preference for the previously rewarded odour (CS+) during retention tests with ants that received control treatment, epinastine, or flupentixol through the food. Each ant completed two retention tests without reward, one five minutes after the sixth learning trial (A), and a second test one day later (B). The ants could move in an arena in which one quadrant was marked with the $\mathrm{CS}+$ odour and another one with CSO. The dotted lines indicate the null hypothesis of ants spending equal time on the CS+ and the CSO; positive values indicate that the ants spend more time in the quadrant marked with the $\mathrm{CS}+$. Numbers above the boxes are sample sizes, * means that the times spent on CS+ and CSO differed (wilcoxon test $p<0.05$ ). For each treatment, standard boxplots and indices of individual ants are plotted. 


\section{Set 2: Topical application}

290 The exact dosage of the receptor blockers is difficult to control when feeding the drugs,

291 because the ants may sometimes ingest more and sometimes less of the food. We thus

292 performed a second set of experiments where we topically applied precise doses of the

293 blockers 30 minutes before the learning trials. During the learning trials, the time it took

294 the ants to find the sugar solution decreased for the control-treated ants (poisson glmm p

$295=0.010, \mathrm{n}=31$ ants; Fig. 4A). This effect was also evident for ants that had been treated

296 with $100 \mathrm{mM}$ epinastine ( $\mathrm{p}<0.001, \mathrm{n}=10$ ants) or flupentixol ( $\mathrm{p}=0.001, \mathrm{n}=30$ ants)

297 previous to the learning trials (Fig. 4B,C). Note that we could only analyse ten of the

298 epinastine learning trials with high dose and none of the ones with low dose.
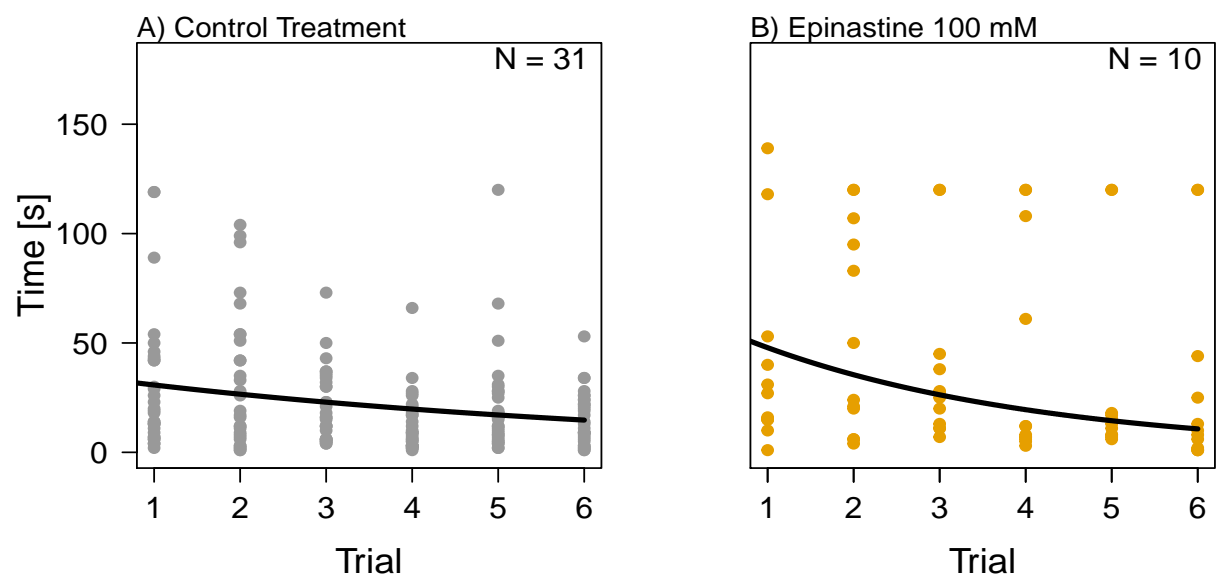

299

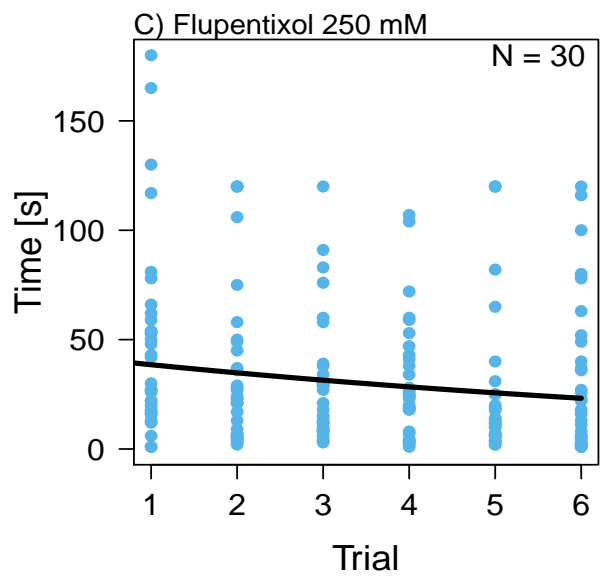

Figure 4: The time it took ants to find the sugar reward in six consecutive learning trials. Ants were either control treated (a), or topically treated with 100mM epinastine (b) or 250mM Flupentixol (c). Lines are from poisson regressions. 
300 In the first retention test, the ants that had been treated only with DMF control preferred

301 the CS+ over the CS0 (Fig. 5A; wilcoxon test $\mathrm{p}<0.001$ ). The same was true for ants

302 that had been treated with $20 \mathrm{mM}$ epinastine (wilcoxon test $\mathrm{p}<0.001$ ) or flupentixol

303 (wilcoxon test $\mathrm{p}<0.001$ ). The ants that had been treated with $100 \mathrm{mM}$ epinastine did

304 not differentiate between the CS + and CS0 on the first day (wilcoxon test $\mathrm{p}=0.83$ ). The

305 preference indices of the $100 \mathrm{mM}$ epinastine treatment were lower than those of the

306 control ants (glmm p $<0.001$, Tab, S3), but those of the $20 \mathrm{mM}$ epinastine treatment ( $\mathrm{p}=$

$3070.45)$ or the flupentixol treatment $(p=0.18)$ were not.

A) Day 1

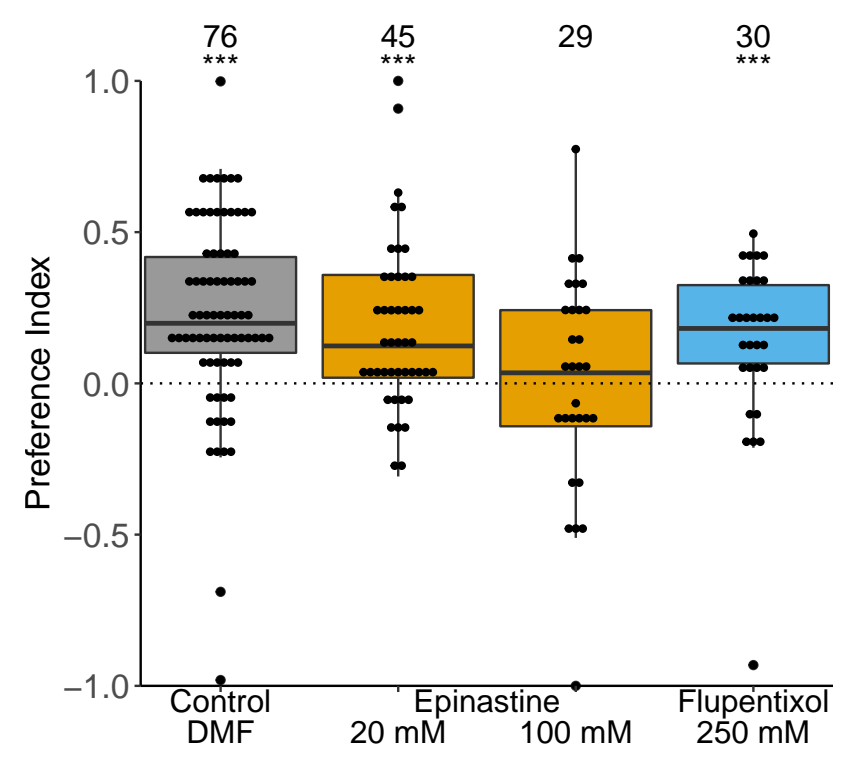

B) Day 2

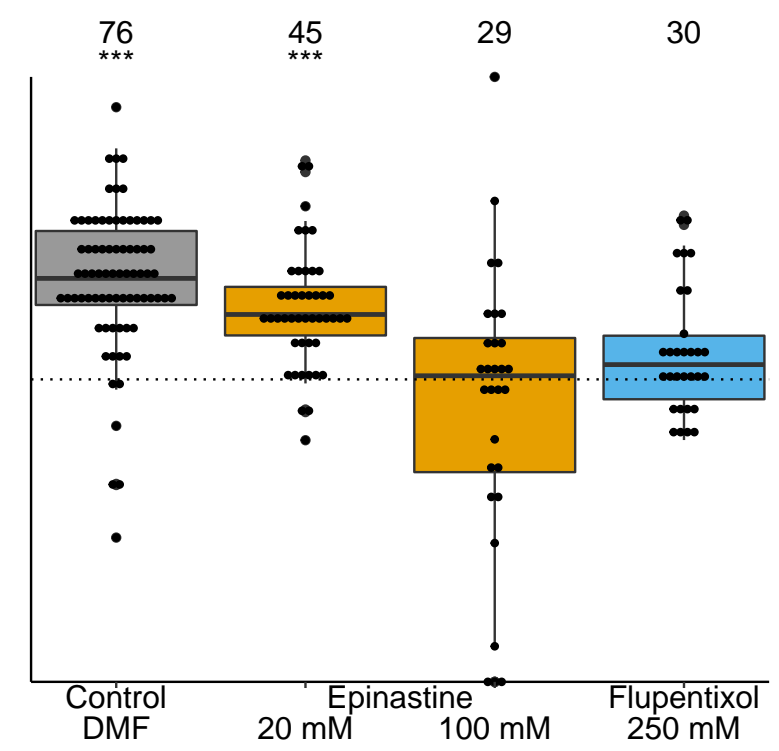

Figure 5: Preference for the CS+ during retention tests with ants that received control treatment, epinastine, or flupentixol through topical application. Each ant completed two retention tests without reward, one five minutes after the sixth learning trial $(A)$ and a second test one day later (B). The ants could move in an arena in which one quadrant was marked with the CS+ odour and another one with CSO. The dotted lines indicate the null hypothesis of ants spending equal time on the CS+ and the CSO; positive numbers indicate that the ants spend more time in the quadrant marked with the CS+. Numbers above the boxes are sample sizes, stars indicate significant differences between the time spent on CS+ and CSO (wilcoxon test; *** $p<0.001$ ). 
309 One day later, the preference for CS+ was still evident for control ants and ants treated

310 with $20 \mathrm{mM}$ epinastine (wilcoxon tests $\mathrm{p}<0.001$ ), and still absent in ants treated with

311 100mM epinastine (wilcoxon test $\mathrm{p}=0.77$ ). There was only a trend for flupentixol-

312 treated ants to discriminate CS + and CS0 ( $\mathrm{p}=0.092$; Figure 5B). However, all ants

313 appeared to be affected by the receptor blockers, as the preference indices of all ants

314 treated with receptor blockers were lower than those of the control ants (glmm, all p <

315 0.05, Tab. S3).

316 To test whether ant learning or memory retrieval may be prevented by a general lethargy

317 caused by the receptor blockers, we tested whether they affected the walking speed of

318 the ants. Indeed, during the first retention test, ants treated with both concentrations of

319 epinastine were slower than control ants (Fig. 6A; glmm p < 0.01; Tab. S4), but

320 flupentixol did not affect walking speed $(p=0.29)$. However, the speed reduction was

321 only in the range of $20 \%$ and should not have prevented the ants from encountering the

322 odours. Indeed, only a single ant, treated with $100 \mathrm{mM}$ epinastine, did not enter the

323 quadrant with the rewarded odour during the retention test. One day later, only the

324 walking speed of epinastine $100 \mathrm{mM}$ ants was reduced (glmm epinastine $\mathrm{p}<0.05$; both

325 other treatments $\mathrm{p}>0.59$; Tab. S4; Fig. 6B).

A) Day 1

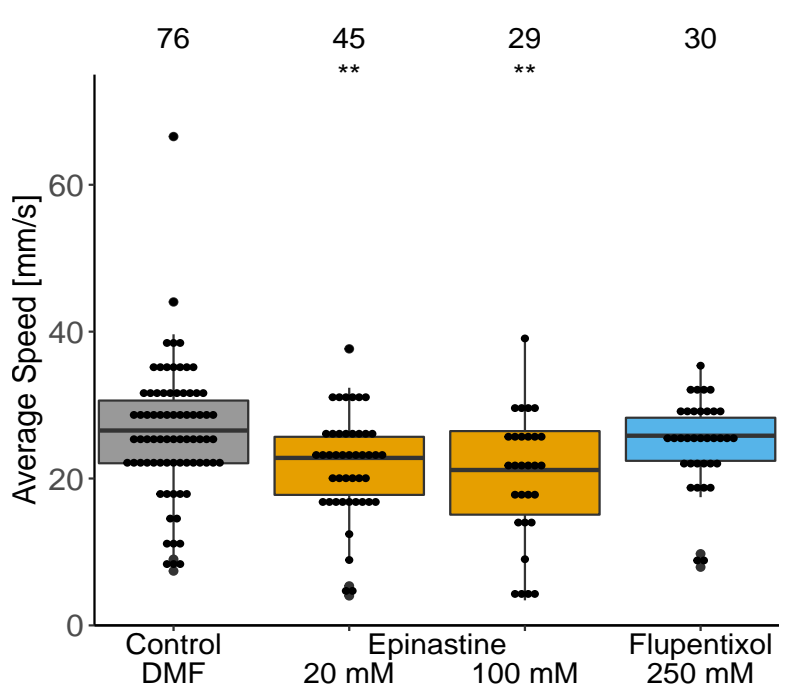

B) Day 2

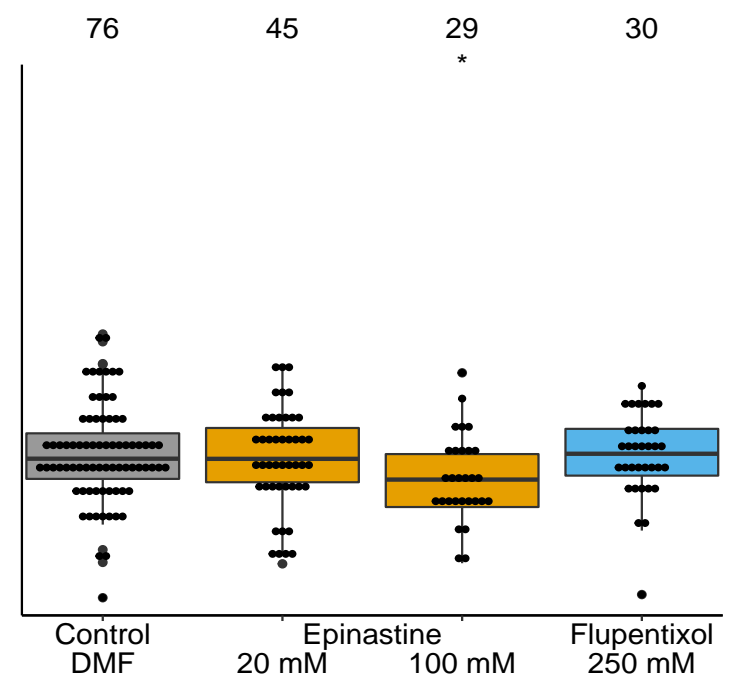

Figure 6. Walking speed during retention tests of control ants and ants that topically received either epinastine or flupentixol. Stars indicate treatments that changed the average speed significantly compared to the control treatment (glmm * $p<0.05 ; * * p<0.01$ ). 


\section{Discussion}

327 Using a classical conditioning protocol, we could show that black garden ant workers

328 can learn to associate blends of linear hydrocarbons with a sucrose reward, and that the

329 memory is stable for at least one day. Exposing the ants to the octopamine receptor

330 blocker epinastine prevented memory formation or retrieval. In contrast, when we

331 exposed the ants to the dopamine receptor blocker flupentixol, the short term memory

332 persisted but the long-term memory was affected. Both octopamine and dopamine

333 signalling are thus involved in the formation of appetitive memory in ants. Our results

334 further suggest that the active period of the receptor blockers is limited in that learning

335 is possible again a few hours after blocker ingestion.

\section{Associating hydrocarbons with a sucrose reward}

337 During the test trials, the ants spent more time on the quadrant that contained the

338 conditioned stimulus (CS+) than that containing a neutral stimulus not previously

339 associated with a sucrose reward (CS0). The increase in time spent in the CS+ quadrant

340 is likely a result of the ants searching for the reward. The ants are thus able to learn and

341 discriminate blends of linear hydrocarbons. Most appetitive conditioning assays in

342 hymenoptera rely on volatile odours that are typically emitted from flowers, to closely

343 resemble the natural situation in which learning can lead to flower constancy in bees

344 (Koethe et al., 2020). However, many pheromones of social insects are less volatile

345 hydrocarbons. Our study confirms previous work on Carpenter Ants and Argentine Ants

346 that demonstrates hydrocarbons are also adequate stimuli for appetitive conditioning,

347 and that the meaning of pheromones and signature mixtures could potentially be

348 changed through learning (Bos et al., 2012; van Wilgenburg et al., 2012; di Mauro et al.,

349 2015; Sharma et al., 2015).

\section{Involvement of octopamine in appetitive learning}

351 Unlike control treated ants, ants that were treated with $100 \mathrm{mM}$ epinastine topically to

352 the thorax did not prefer the conditioned hydrocarbon odour over a non-conditioned

353 odour within five minutes after the learning trials, and neither did they prefer the

354 conditioned stimulus after a break of one day. As epinastine blocks octopamine 
355 receptors, this shows that octopamine signalling is required for the formation of short

356 and long term memory of appetitive stimuli in ants, potentially because octopaminergic

357 neurons relay the unconditioned stimulus to the Kenyon cells (e.g. VUMx1 in bees,

358 Rein et al., 2013). Our findings confirm previous work demonstrating such an effect in

359 fruit flies, honey bees, and crickets (Schwaerzel et al., 2003; Giurfa, 2007; Mizunami

360 and Matsumoto, 2017).

361 Epinastine does not only affect memory but potentially also other traits. Under the

362 influence of epinastine, silkmoths were less sensitive for pheromones (Pophof 2000),

363 the metabolism of hungry honeybees was reduced (Buckenmüller et al.,2017), and

364 aggression was modulated in crickets and red wood ants (Rillich and Stevenson 2011,

365 2018; Yakovlev, 2018). In our study, the mobility of ants treated with epinastine was

366 reduced during the first retention test. For the high dose of epinastine, this effect was

367 still visible one day later, which may indicate that epinastine is only slowly degraded.

368 However, the ants still visited all quadrants of the arena during the retention tests, and

369 they also reacted to the sucrose solution during the learning trials. We thus argue that the

370 failure to identify the CS+ in the retention tests is not due to a decrease of motivation or

371 even an inability to walk, but due to a lack of memory formation or retrieval. In fact, in

372 all our learning trials with epinastine-treated ants, the time until the ants found the

373 sucrose solution decreased. A simple explanation would be that the ants do learn to

374 expect sucrose in the arena and search for it, which decreases search time, but they do

375 not associate it with the odour and thus do not spend more time with the previously

376 rewarded odour in the non-rewarded retention trials.

377 Ants topically treated with a lower dose of epinastine were not impaired in their

378 learning ability. More interestingly, the effects were still visible when we fed epinastine

379 with the food, but weaker than when we directly applied the drug to the thorax. It is

380 possible that only part of the dose is entering the hemolymph when the drugs are taken

381 up with the food. Ant workers possess a crop used to store food that is later regurgitated

382 to feed nestmates (Greenwald et al., 2018). Some epinastine entering the crop may thus

383 never reach the octopamine receptors in the brain, exposing them to lower doses than

384 intended. It may take a while until epinastine is taken up into the hemolymph and

385 reaches the brain, meaning that it will take action only after a certain delay (but see 
386 Barron et al., 2007: octopamine delivered through the food reaches the honey bee brain

387 in less than one hour). We thus fed the ants epinastine at different intervals before

388 subjecting them to the learning trials. However, longer intervals only reduced the effect

389 of epinastine, and ca. 20 hours after being fed the receptor blockers, the preference

390 indices of epinastine-fed individuals were no different than those of control ants.

391 Finally, when ants were fed epinastine, we found only weak effects on the short term

392 memory retention. Given that there was a clear effect on the short term memory when

393 epinastine was topically applied, this might have to do with long and short term memory

394 being formed in different parts of the brain (e.g. different populations of Kenyon cells,

395 Sachse and Galizia, 2003) and potentially at different times. If short term memory

396 formation is quicker than long term memory formation, epinastine may have reached

397 the brain before the long term memory formation, but after short term memory

398 formation was complete.

\section{Involvement of dopamine}

400 In our experiments, flupentixol strongly affected the long term memory as well, but not

401 necessarily the short term memory. After topical application, we did not find any

402 evidence of flupentixol affecting the short term memory. Flupentixol blocks dopamine

403 receptors, so that our observation suggest that the dopaminergic neurons are probably

404 not required in ants to relay the unconditioned stimulus to the Kenyon cells (as it is in

405 fruit flies and bees, Schwaerzel et al., 2003; Giurfa, 2007). However, we found weak

406 effects of flupentixol on the short term memory when we fed it to the ants, which may

407 indicate that a functional dopaminergic system may improve learning performance.

408 In contrast to the short term memory, the long term memory was always affected when

409 we administered flupentixol via either food or topical application. It is particularly

410 curious that this even happened after topical application of flupentixol, when ants still

411 clearly preferred the rewarded stimulus in the short term memory retention tests. This

412 indicates a necessary involvement of dopaminergic neurons in the consolidation phase

413 of long term memory formation that is independent of the short term memory and

414 cannot be rescued by octopaminergic neurons, which are still functioning when only

415 flupentixol is administered. The dopaminergic neurons may thus not be relaying the 
416 unconditioned stimulus to the learning centres, but be part of feedback loops or

417 modulation pathways (Eschbach et al., 2020). Long term memory formation is a more

418 complex process than short term memory formation (e.g. Menzel, 1999; Villar, 2020)

419 and memory consolidation might rely on additional neural circuits that could be

420 dopaminergic. For example, some lateral neurons in the antennal lobes are

421 dopaminergic (Galizia and Sachse, 2010) and might be used to improve the perception

422 of relevant odours such as the CS+. In the mushroom body, Kenyon cells receive

423 feedback from the primary protocerebral anterior cluster via dopaminergic neurons in

424 fruit fly larvae (Lyutova et al., 2019).

425 Blocking dopamine receptors does not only influence appetitive and aversive learning.

426 Blocking the AmDOP2 receptor has led to reduced motor behaviours and an increase of

427 grooming in honey bees (Mustard et al., 2010). In Drosophila, social interactions and

428 temperature preferences seem to be affected (Verlinden, 2018). In our study, there was

429 no evidence of effects on motor behaviour, since walking speed of flupentixol-treated

430 ants did not differ from that of control ants. Interestingly though, flupentixol fed 5-8

431 hours before learning, the treatment that affected both the short and the long term

432 memory, also prevented an improvement of the times the ants needed to find the reward

433 during the learning trials (Fig. 2). Also, in the flupentixol-treated groups, particularly

434 many individuals did not find the sucrose reward during the two minutes of the learning

435 trial (Tab. S1). One possible explanation could be that blocking dopamine signalling

436 interferes with the motivational state of the ants. If lack of dopamine signalling would

437 make them believe they were not hungry, they might not be primed to seek the sucrose

438 reward in the learning trials, but may still be drawn to the conditioned stimulus in the

439 retention tests because of its familiarity. Indeed, dopamine is important for hunger

440 signalling in Drosophila (Krashes et al. 2009; Siju et al., 2021). Hunger affects the

441 motivational state, which is important for memory formation and retrieval because

442 satiated flies do not seek food. However, dopaminergic neurons appear to signal

443 satiation rather than hunger in Drosophila, so that blocking them should improve

444 motivation and thus memory formation (Krashes et al., 2009). If the neural circuits were

445 similar in ants, hunger could thus not explain the curious pattern caused by blocking

446 dopamine receptors. However, the motivation of ants as social beings is perhaps

447 regulated less by their personal physiological hunger and more by that of their colony, 
448 so that entirely different regulatory circuits might be involved here (e.g. Cholé et al.,

449 2019). In any case, such a lack of hunger or motivation could only explain an effect of

450 flupentixol on the short term memory in the feeding trial: In the topical application

451 experiment, ants did initially learn in learning trials and remembered in the first

452 retention test, but clearly failed to remember on the next day. This observation indicates

453 an involvement of dopamine in the consolidation of the long term memory, independent

454 short term memory formation and motivation.

\section{Conclusions}

456 Lasius niger ants can learn to associate mixtures of linear hydrocarbons to a sugar

457 reward and remember the association for at least 24 hours. Both octopamine and

458 dopamine appear to be involved in memory formation, with strong effects of a

459 pharmacological octopamine knockout on both the short and the long term memory.

460 Dopamine signalling is required for the formation of the long term memory but not

461 necessarily for the short term memory.

\section{Acknowledgements}

464 We would like to thank the members of the Department of Ecology and Evolution,

465 University of Freiburg, Germany, and Andrew Straw for fruitful discussions. Thanks to

466 Mélanie Bey for helpful comments on a previous version of the manuscript, and to the

467 German Research Foundation (DFG grant) for funding. 


\section{Literature}

469 Agarwal, M., Guzman, M. G., Morales-Matos, C., Del Valle Diaz, R. A., Abramson,

470 C. I., and Giray, T. (2011). Dopamine and Octopamine Influence Avoidance Learning

471 of Honey Bees in a Place Preference Assay. PLoS ONE 6(9), e25371.

473 Awata, H., Watanabe, T., Hamanaka, Y., Mito, T., Noji, S. and Mizunami, M.

474 (2015). Knockout crickets for the study of learning and memory: Dopamine receptor

475 Dop1 mediates aversive but not appetitive reinforcement in crickets. Sci. Rep. 5(1),

47615885.

478 Barron, A. B., Maleszka, J., Vander Meer, R. K., Robinson, G. E. andMaleszka, R.

479 (2007). Comparing injection, feeding and topical application methods for treatment of

480 honeybees with octopamine. J. Insect Physiol. 53(2), 187-194.

482 Beggs, K. T., Tyndall, J. D. A. and Mercer, A. R. (2011). Honey Bee Dopamine and

483 Octopamine Receptors Linked to Intracellular Calcium Signaling Have a Close

484 Phylogenetic and Pharmacological Relationship. PLoS ONE 6(11), e26809.

486 Berry, J.A., Cervantes-Sandoval, I., Nicholas, E.P. and Davis, R.L. (2012).

487 Dopamine Is Required for Learning and Forgetting in Drosophila. Neuron 74(3), 530488542.

490 Bos, N., Guerrieri, F. J. and d'Ettorre, P. (2010). Significance of chemical

491 recognition cues is context dependent in ants. Anim. Behav. 80, 839-844. 
492 Bos, N., Dreier, S., Jorgensen, C. G., Nielsen, J., Guerrieri, F. J. and d'Ettorre, P.

493 (2012). Learning and perceptual similarity among cuticular hydrocarbons in ants. $J$.

494 Insect Physiol. 58(1), 138-146.

496 Buckemüller, C., Siehler, O., Göbel, J., Zeumer, R., Ölschläger, A. and Eisenhardt,

497 D. (2017). Octopamine Underlies the Counter-Regulatory Response to a Glucose

498 Deficit in Honeybees (Apis mellifera). Front. Syst. Neurosci. 11, 63.

500 Cholé, H., Carcaud, J., Mazeau, H., Famié, S., Arnold, G. andSandoz, J.-C. (2019).

501 Social Contact Acts as Appetitive Reinforcement and Supports Associative Learning in

502 Honeybees. Curr. Biol. 29(8), 1407-1413.

504 Claßen, G. and Scholz, H. (2018). Octopamine Shifts the Behavioral Response From

505 Indecision to Approach or Aversion in Drosophila melanogaster. Front. Behav.

506 Neurosci. 12, 131.

508 di Mauro, G., Perez, M., Lorenzi, M. C., Guerrieri, F. J., Millar, J. G. and

509 d'Ettorre, P. (2015). Ants Discriminate Between Different Hydrocarbon

510 Concentrations. Front. Ecol. Evol. 3, 133.

512 Eschbach, C., Fushiki, A., Winding, M., Schneider-Mizell, C. M., Shao, M.,

513 Arruda, R., Eichler, K., Valdes-Aleman, J., Ohyama, T., Thum, A. S., Gerber, B.,

514 Fetter, R. D., Truman, J. W., Litwin-Kumar, A., Cardona, A. and Zlatic, M. (2020).

515 Recurrent architecture for adaptive regulation of learning in the insect brain. Nat.

516 Neurosci. 23(4), 544-555. 
518 Fernandes, A. S. D., Buckley, C. L. and Niven, J. E. (2018). Visual associative

519 learning in wood ants. J. Exp. Biol. 221(3), jeb173260.

521 Galizia, C. G. and Sachse, S. (2010). Odor Coding in Insects. In The Neurobiology of

522 Olfaction (ed. A. Menini), pp. 35-70. Boca Raton (FL): CRC Press.

524 Giurfa, M. (2007). Behavioral and neural analysis of associative learning in the

525 honeybee: a taste from the magic well. J Comp Physiol A Neuroethol Sens Neural

526 Behav Physiol. 93, 801-824.

528 Greenwald, E. E., Baltiansky, L. and Feinerman, O. (2018). Individual crop loads

529 provide local control for collective food intake in ant colonies. ELife 7, e31730.

531 Guerrieri, F. J. and d'Ettorre, P. (2010). Associative learning in ants: Conditioning of

532 the maxilla-labium extension response in Camponotus aethiops. J. Insect Physiol. 56(1),

533 88-92.

535 Guerrieri, F. J., d'Ettorre, P., Devaud, J. M. and Giurfa, M. (2011). Long-term

536 olfactory memories are stabilised via protein synthesis in Camponotus fellah ants. $J$.

537 Exp. Biol. 214(19), 3300-3304.

538 Hadfield, J. (2010). MCMC Methods for Multi-Response Generalized Linear Mixed

539 Models: TheMCMCglmmRPackage J. Stat. Softw. .33(2), 10.18637/jss.v033.i02. 
541 Hammer, M. and Menzel, R. (1998). Multiple sites of associative odor learning as

542 revealed by local brain microinjections of octopamine in honeybees. Learn Mem. 5(1), 543 146-56.

545 Hige, T., Aso, Y., Modi, M. N., Rubin, G.M. and Turner, G. C. (2015).

546 Heterosynaptic Plasticity Underlies Aversive Olfactory Learning in Drosophila. Neuron 547 88(5), 985-998.

549 Kamhi, J. F., Nunn, K., Robson, S. K. A. and Traniello, J. F. A. (2015).

550 Polymorphism and division of labour in a socially complex ant: neuromodulation of 551 aggression in the Australian weaver ant, Oecophylla smaragdina. Proc. Royal Soc. B

554 Koethe, S., Fischbach, V., Banysch, S., Reinartz, L., Hrncir, M. and Lunau, K. A

555 (2020). Comparative Study of Food Source Selection in Stingless Bees and Honeybees:

556 Scent Marks, Location, or Color. Front. Plant Sci. 11, 516. .

558 Krashes, M. J., DasGupta, S., Vreede, A., White, B., Armstrong, J. D. andWaddell,

559 S. (2009). A neural circuit mechanism integrating motivational state with memory

560 expression in Drosophila. Cell 139(2), 416-427.

562 Leonhardt, S. D., Menzel, F., Nehring V., Schmitt, T. (2016). Ecology and Evolution 563 of Communication in Social Insects, Cell 164(6), 1277-1287. 
565 Lyutova, R., Pfeuffer, M., Segebarth, D., Habenstein, J., Selcho, M., Wegener, C.,

566 Thum, A.S. and Pauls, D. (2019). Reward signaling in a recurrent circuit of

567 dopaminergic neurons and peptidergic Kenyon cells. Nat. Commun. 10, 3097.

569 Mancini, N., Giurfa, M., Sandoz, J. C. and Avarguès-Weber, A. (2018). Aminergic

570 neuromodulation of associative visual learning in harnessed honey bees. Neurobiol.

571 Learn. Mem. 155., 556-567.

573 Mathis, A., Mamidanna, P., Cury, K. M., Murthy, V. N., Mathis, M. W. and Bethge,

574 M. (2018). DeepLabCut: markerless pose estimation of user-defined body parts with

575 deep learning. Nat. Neurosci. 21, 1281-1289.

577 Menzel, R. (1999). Memory dynamics in the honeybee. J Comp Physiol A 185, 323578340.

580 Menzel, R. (2014). The insect mushroom body, an experience-dependent recording 581 device. J. Physiol. Paris 108, 84-95.

582 Mizunami, M. and Matsumoto, Y. (2017). Roles of Octopamine and Dopamine

583 Neurons for Mediating Appetitive and Aversive Signals in Pavlovian Conditioning in 584 Crickets. Front. Physiol. 8, 1027. 
586 Mustard, J. A., Blenau, W., Hamilton, I. S., Ward, V. K., Ebert, P. R. and Mercer,

587 A. R. (2003). Analysis of two D1-like dopamine receptors from the honey bee Apis

588 mellifera reveals agonist-independent activity. Mol. Brain Res. 113(1-2), 67-77.

590 Mustard, J. A., Pham, P. M. and Smith, B. H. (2010). Modulation of motor behavior

591 by dopamine and the D1-like dopamine receptor AmDOP2 in the honey bee. J. Insect

592 Physiol. 56(4), 422-430.

594 Neupert, S., Hornung, M., Grenwille Millar, J. and Kleineidam, C. J. (2018).

595 Learning Distinct Chemical Labels of Nestmates in Ants. Front. Behav. Neurosci. 12, 596191.

598 Ottoni, E. B. (2000). EthoLog 2.2: A tool for the transcription and timing of behavior

599 observation sessions. Behav. Res. Methods Instrum. Comput. 32(3), 446-449.

600

601 Perisse, E., Yin, Y., Lin, A. C., Lin, S., Huetteroth, W. and Waddell, S. (2013).

602 Different kenyon cell populations drive learned approach and avoidance in Drosophila.

603 Neuron 79(5), 945-956.

604

605 Perry, C. J. and Barron, A. B. (2013). Neural Mechanisms of Reward in Insects.

606 Annu. Rev. Entomol. 58, 543-562. 
608 Piqueret, B., Sandoz, J.-C., and d'Ettorre, P. (2019). Ants learn fast and do not

609 forget: Associative olfactory learning, memory and extinction in Formica fusca. R. Soc.

610 Open Sci. 6(6), 190778.

612 Pophof, B. (2000). Octopamine modulates the sensitivity of silkmoth pheromone

613 receptor neurons. J. Comp. Physiol A. 186(3), 307-13.

615 Qi, Y. X., Xu, G., Gu, G. X., Mao, F., Ye, G. Y., Liu, W. and Huang J. (2017). A new

616 Drosophila octopamine receptor responds to serotonin. Insect. Biochem. Mol. Biol. 90, 617 61-70.

619 R Core Team (2020). R: A language and environment for statistical computing. R

620 Foundation , Vienna, Austria. URL https://www.R-project.org/

622 Rein, J., Mustard, J. A., Strauch, M., Smith, B. H. and Galizia, C. G. (2013).

623 Octopamine modulates activity of neural networks in the honey bee antennal lobe. $J$.

624 Comp. Physiol. A 199, 947-962.

625

626 Rillich, J. and Stevenson, P.A. (2011). Winning fights induces hyperaggression via the

627 action of the biogenic amine octopamine in crickets. PLoS One. 6(12), e28891.

629 Rillich, J. and Stevenson, P.A. (2018). Serotonin Mediates Depression of Aggression

630 After Acute and Chronic Social Defeat Stress in a Model Insect. Front. Behav.

631 Neurosci. 12, 233. 
633 Roeder, T., Degen, J. and Gewecke, M. (1998). Epinastine, a highly specific

634 antagonist of insect neuronal octopamine receptors. Eur. J. Pharmacol. 349(2-3), 171-

635177.

636

637 Rohwedder, A., Wenz, N. L., Stehle, B., Huser, A., Yamagata, N., Zlatic, M.,

638 Truman, J. W., Tanimoto, H., Saumweber, T., Gerber, B. and Thum, A. S. (2016).

639 Four Individually Identified Paired Dopamine Neurons Signal Reward in Larval

640 Drosophila. Curr. Biol. 26, 661-669.

642 Sabandal, J. M, Sabandal, P. R., Kim, Y.-C. and Han, K.-A. (2020) Concerted

643 Actions of Octopamine and Dopamine Receptors Drive Olfactory Learning. $J$.

644 Neurosci. 40(21), 4240-4250.

646 Sachse, S. and Galizia, C. G. (2003). The Coding of Odour-Intensity in the Honeybee

647 Antennal Lobe: Local Computation Optimizes Odour Representation. Eur. J.

648 Neurosci.18, 2119-2132.

650 Schwaerzel, M., Monastirioti, M., Scholz, H., Friggi-Grelin, F., Birman, S. and

651 Heisenberg, M. (2003). Dopamine and Octopamine Differentiate between Aversive and

652 Appetitive Olfactory Memories in Drosophila. J. Neurosci 23 (33), 10495-10502.

654 Sharma, K. R., Enzmann, B. L., Schmidt, Y., Moore, D., Jones, G. R., Parker, J.,

655 Berger, S. L, Reinberg, D., Zwiebel, L. J., Breit, B., Liebig, J., Ray, A. (2015). 
656 Cuticular Hydrocarbon Pheromones for Social Behavior and Their Coding in the Ant

657 Antenna. Cell Rep. 12(8), 1261-1271.

658

659 Siju, K. P., De Backer, J. F. \& Grunwald Kadow, I. C. (2021). Dopamine modulation

660 of sensory processing and adaptive behavior in flies. Cell Tissue Res. 383, 207-225 (.

661

663 M. A. and Tsutsui, N. D. (2012) Learning and discrimination of cuticular hydrocarbons

664 in a social insect. Biol. Lett. 8, 17-20

665

666 Vergoz, V., Roussel, E., Sandoz, J. C. and Giurfa, M. (2007). Aversive Learning in

667 Honeybees Revealed by the Olfactory Conditioning of the Sting Extension Reflex.

668 PLOS ONE 2(3), e288.

669

670 Verlinden, H. (2018). Dopamine signalling in locusts and other insects. Insect

671 Biochem. Mol. Biol. 97,40-52.

673 Villar, M. E., Marchal, P., Viola, H. and Giurfa, M. (2020) Redefining Single-Trial

674 Memories in the Honeybee. Cell Rep. 30(8),2603-2613.

675

676 Wickham, H. (2016). ggplot2: Elegant Graphics for Data Analysis. New York, US:

677 Springer-Verlag. 
bioRxiv preprint doi: https://doi.org/10.1101/2021.04.19.438615; this version posted April 19, 2021. The copyright holder for this preprint (which was not certified by peer review) is the author/funder, who has granted bioRxiv a license to display the preprint in perpetuity. It is made available under aCC-BY-ND 4.0 International license.

679 Xu, G., Chang, X. F., Gu, G. X., Jia, W. X., Guo, L., Huang, J. and Ye, G. Y. (2020).

680 Molecular and pharmacological characterization of a $\beta$-adrenergic-like octopamine

681 receptor from the green rice leafhopper Nephotettix cincticeps. Insect. Biochem. Mol.

682 Biol. 120, 103337.

683

684 Yakovlev, I.K. (2018) Effects of Octopamine on Aggressive Behavior in Red Wood

685 Ants. Neurosci. Behav. Physi. 48, 279-288. 